\title{
Age models, chronologies, and databases workshop
}

\author{
Eric C. Grimm¹, M. Blaauw², C.E. Buck ${ }^{3}$ and J.W. Williams ${ }^{4}$ \\ Belfast, UK, 13-16 January 2014
}

\begin{abstract}
Paleo databases are critical cyberinfrastructure for paleoenvironmental research, especially for broad scale synoptic studies that place current environmental and climatic changes in context. Chronological control is critical for paleo studies, and chronologies and age models are essential metadata for paleo databases. Paleo databases typically comprise a large number of individual datasets acquired over a long time period. A major challenge for database managers and users is that criteria for estimating chronologies change through time rendering existing chronologies obsolete. In particular, chronologies based on calibrated radiocarbon ages become obsolete with each revision of the calibration curve, regardless of the sophistication of the age modeling technique. In addition, age modeling software has also evolved over the years. New programs, often using Bayesian techniques (Fig. 1), can now provide estimates of the uncertainties for interpolated sample ages. Most age models currently archived do not provide these uncertainties, which are nevertheless critical for assessing the statistical robustness of synchronous change across multiple sites and datasets.
\end{abstract}

To address these issues, 35 scientists from 12 countries met at the Queen's University Belfast
${ }^{14} \mathrm{CHRONO}$ Centre for a three-day workshop, which was followed by a one-day software training session attended by an additional eight participants focusing on the clam (Blaauw 2010) and Bacon (Blaauw and Christen 2011) age modeling programs. Initially, the Neotoma Paleoecology Database (www.neotomadb.org) had funding to support a small workshop of its Age Modeling Working Group. Additional funding from PAGES and the US National Science Foundation made it possible to also invite students and scientists involved with other database projects.

During the first day of the workshop, speakers discussed how various databases handle age modeling and chronology issues, calibration of radiocarbon dates, age modeling software, and database interoperability. During the following two days, breakout groups addressed the following topics: (1) Age models based on radiocarbon dating: problems caused by updates to the calibration curve; (2) Age models based on radiocarbon dating: strategies for regenerating chronologies from stored chronological data and age-model metadata; (3) Age models beyond the radiocarbon time scale; (4) Strategies for reducing the need for ad hoc age models; (5) Rankings of the quality

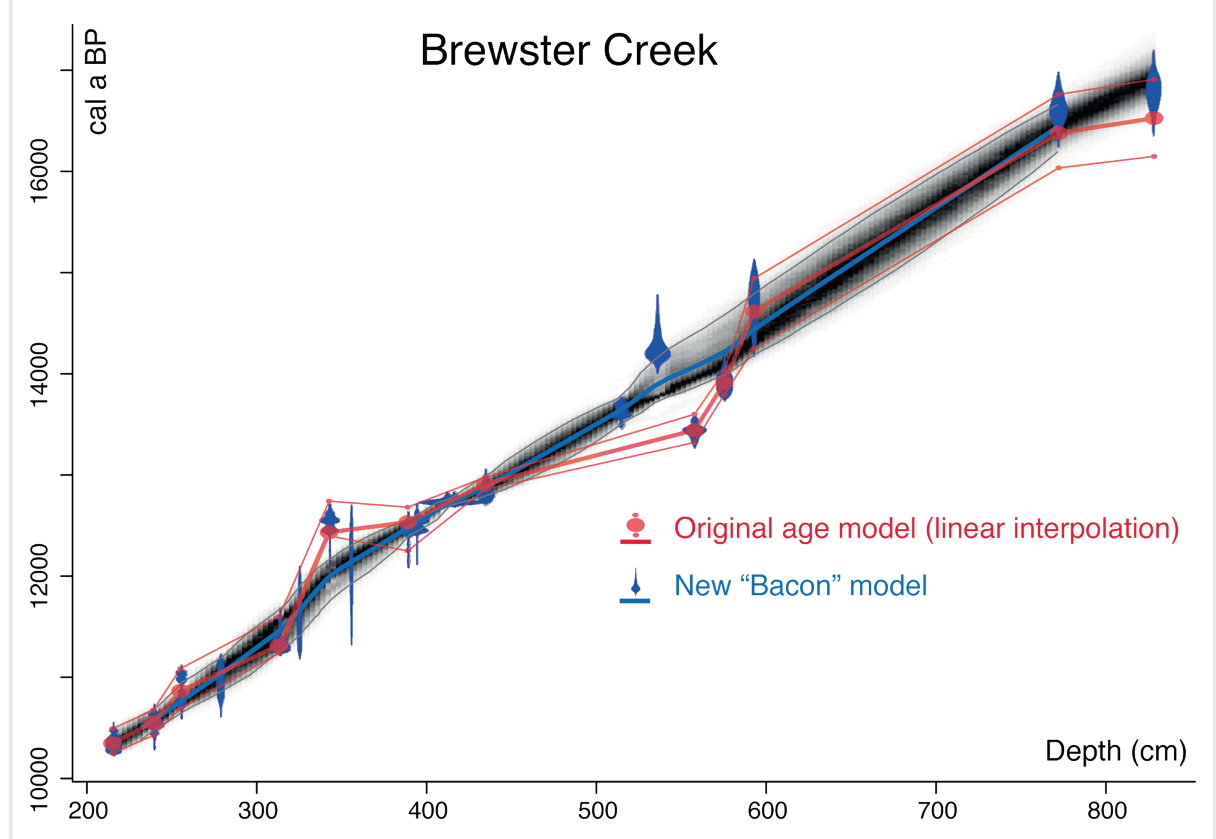

Figure 1: New Bayesian age model for the Brewster Creek (USA) site produced by the Bacon program (Blaauw and Christen 2011) overlaid with the published classical model (Curry et al 2007). The original model is based on the IntCal04 calibration curve, linear interpolation, and ad hoc rejection of reversed dates; while the Bacon model is based on the IntCal13 curve and can accommodate reversed dates. The gray-scale shading represents the relative probability within the $95 \%$ higher posterior density region (or Bayesian confidence interval). The thick red line is the linear interpolation between the median probabilities of the calibrated ages in the original model; the thin red lines connect the $95 \%$ confidence limits of the calibrated ages but are not a valid statistical representation of the confidence limits of the interpolated ages. and accuracy of dates and chronologies; and (6) Linking databases, calibration programs, and age modeling programs.

The summarized workshop recommendations* are: (1) Chronologies reported in the literature and stored in databases must be reproducible, and publications and databases should store sufficient data and metadata to ensure reproducibility. (2) The output from age modeling software should provide all the information necessary to reproduce age models in easily storable scripts or "age model definition" files, and a common metadata standard should be developed for these files. (3) Databases should archive originally published chronologies; however, database managers cannot be expected to reconstruct chronologies unless sufficient data and metadata are published or otherwise provided to them. (4) Because updates to the radiocarbon calibration curve and new modeling approaches may render published age models obsolete, database managers are encouraged to generate updated age models or to store those developed by other scientists. (5) Because ad hoc models that use different age modeling algorithms for different sections of a stratigraphic sequence are often difficult to reproduce, developers of age modeling software are encouraged to formally incorporate instantaneous sedimentation events, hiatuses, and sharp changes in sedimentation rate into their modeling frameworks. (6) An international open-access database for radiocarbon dates should be developed, and purchasers of radiocarbon dates should be given the option by the radiocarbon laboratories, and encouraged by funding agencies, to contribute their dates to the database.

*Complete recommendations of the workshop are available at:

www.pages-igbp.org/calendar/127-pages/826-age-models-chronologies-and-databases

\section{AFFILIATIONS}

${ }^{1}$ Illinois State Museum, Springfield, USA

${ }^{2} S c h o o l$ of Geography, Archaeology and Palaeoecology,

Queen's University Belfast, Northern Ireland, UK

${ }^{3}$ School of Mathematics and Statistics, University of Sheffield, UK

${ }^{4}$ Department of Geography, University of WisconsinMadison, USA

\section{CONTACT}

Eric C. Grimm: grimm@museum.state.il.us

\section{REFERENCES}

Blaauw M (2010) Quat Geochron 5: 512-518

Blaauw M, Christen JA (2011) Bayesian Anal 6: 457-474

Curry BB et al. (2007) Illinois State Geol Surv Circ 571 